\title{
Physicochemical factors differentially affect the biomass and bacteriocin production by bovine Enterococcus mundtii CRL1656
}

\author{
M. Carolina Espeche, ${ }^{\star}$ M. Silvina Juárez Tomás, ${ }^{*}$ Birgitt Wiese, $†$ Elena Bru, ${ }^{\star}$ and M. E. Fátima Nader-Macías ${ }^{\star 1}$ \\ ${ }^{*}$ Centro de Referencia para Lactobacilos, Consejo Nacional de Investigaciones Científicas y Técnicas de Argentina, \\ 4000 San Miguel de Tucumán, Argentina \\ †Institut für Biometrie, Medizinische Hochschule, 30625 Hannover, Germany
}

\section{ABSTRACT}

Bovine Enterococcus mundtii CRL1656 (Centro de Referencia para Lactobacilos Culture Collection) produces an anti-Listeria and anti-Streptococcus dysgalactiae bacteriocin identified as mundticin CRL1656. The strain and its bacteriocin are candidates to be included in a beneficial product to prevent bovine mastitis as an alternative to antimicrobial agents. To optimize the production of biomass and mundticin CRL1656 by $E$. mundtii CRL1656, a complete $3 \times 2^{4}$ factorial design was applied. The effect of culture medium, initial $\mathrm{pH}$, inoculum size, incubation temperature, and agitation conditions on biomass and bacteriocin production was evaluated simultaneously. Growth parameters were determined using the modified Gompertz model. A nonlinear model was used to estimate the effects of the variables on growth parameters. Bacteriocin production was analyzed using a linear mixed model. Optimal biomass and mundticin CRL1656 production by $E$. mundtii CRL1656 were obtained in different conditions. Maximal growth was recorded in autolyzed yeast, peptone, tryptone, Tween 80, and glucose or M17 broths, $\mathrm{pH} 6.5,5.0 \%$ inoculum, $30^{\circ} \mathrm{C}$, with agitation. However, bacteriocin titers were higher in autolyzed yeast, peptone, tryptone, Tween 80 , and glucose or de Man-Rogosa-Sharpe (MRS) broths, $\mathrm{pH} 6.5,30^{\circ} \mathrm{C}$, both with or without agitation. Knowledge of the optimum conditions for growth and bacteriocin production of $E$. mundtii CRL1656 will allow the obtainment of high levels of biomass and mundticin CRL1656 as bioingredients of potential products to prevent bovine mastitis. Key words: mundticin production, Enterococcus mundtii, bovine mastitis prevention, lactic acid bacterium

Received May 27, 2013.

Accepted October 28, 2013.

${ }^{1}$ Corresponding author: fnader@cerela.org.ar

\section{INTRODUCTION}

Bovine mastitis (i.e., the inflammation of the bovine mammary gland) produces a negative economic effect on dairy farms (Huijps et al., 2008). This disease is mainly caused by pathogenic or environmental bacteria, such as Staphylococcus aureus, coagulase-negative Staphylococcus, Streptococcus agalactiae, Escherichia coli, and Streptococcus dysgalactiae, that cause infection once they pass through the teat canal (Sears and McCarthy, 2003; Barkema et al., 2009; Taponen and Pyörälä, 2009). During the dry period, animals are more susceptible to infections, and dry cow therapies are applied to treat or prevent new cases of mastitis. Antimicrobial agents are administered without taking into account the fact that the overuse of these drugs could result in a selective pressure for antimicrobialresistant organisms. Moreover, conventional antimicrobial therapy can also generate residues in the milk, which must then be discarded (Huijps et al., 2008).

Teat disinfection is an important strategy in mastitis control programs. Different substances, such as iodophors, lactic acid, FA, and nisin, have been tested as teat sanitizers (Boddie and Nickerson, 1992; Sears et al., 1992; Boddie et al., 2004). Beneficial microorganisms (Klostermann et al., 2008; Beecher et al., 2009; Frola et al., 2012) and bacteriocins from lactic acid bacteria (LAB), such as nisin (Sears et al., 1992; Cao et al., 2007), lacticin 3147 (Crispie et al., 2004; Klostermann et al., 2010) and macedocin ST91KM (Pieterse et al., 2008, 2010; Pieterse and Todorov, 2010), have been proposed as alternatives for the prevention or treatment of bovine mastitis. Products containing viable beneficial microorganisms, supplemented or not with bacteriocins, can be administered as intramammary treatments (to prevent or treat infections) or as external teat treatments applied to the udder skin (to prevent infections).

Bacteriocin-producing Enterococcus mundtii CRL1656 [from the Centro de Referencia para Lactobacilos (CERELA) Culture Collection, Tucumán, Argentina], an autochthonous strain isolated from bovine udder, was previously characterized and selected 
as a beneficial microorganism (Espeche et al., 2009). This strain produces mundticin CRL1656, a type II bacteriocin active against a bovine mastitis pathogen (Strep. dysgalactiae) and a food-borne pathogen (Listeria monocytogenes Scott A). Both autochthonous E. mundtii CRL1656 and its bacteriocin are potential candidates to be included in the design of veterinary products for mastitis prevention.

Physicochemical factors, such as $\mathrm{pH}$, temperature, culture medium composition, and agitation conditions, influence biomass and bacteriocin production by different LAB strains (Nel et al., 2001; Juarez Tomás et al., 2002; Van den Berghe et al., 2006). Several authors have indicated that optimal culture conditions are strain dependent and should be adjusted for each microorganism (Mataragas et al., 2003; De Vuyst and Leroy, 2007; Settanni et al., 2008).

Some bacteriocin-producing E. mundtii strains isolated mainly from vegetables matrices have been described and proposed for the biopreservation of plant-related foods (Granger et al., 2005; Zendo et al., 2005; Settanni et al., 2008). Enterococcus mundtii CRL35, a strain isolated from an artisanal cheese, produces enterocin CRL35, which exerts an inhibitory effect on the growth of spoilage and pathogenic microorganisms (Salvucci et al., 2012; Vera Pingitore et al., 2012). The effect of different environmental factors on the production of bacteriocins synthesized by some $E$. mundtii strains has already been studied (De Kwaadsteniet et al., 2005; Zendo et al., 2005; Settanni et al., 2008; Todorov and Dicks, 2009). However, bacteriocin and biomass production by a bovine E. mundtii strain, which is proposed as a potential probiotic for mastitis prevention in this work, has not been reported to date. The aim of the current study was to determine the combined effects of culture medium, initial $\mathrm{pH}$, inoculum size, incubation temperature, and agitation conditions on biomass and bacteriocin production by bovine E. mundtii CRL1656, applied using a complete $3 \times 2^{4}$ factorial design.

\section{MATERIALS AND METHODS}

\section{Bacterial Strains and Culture Conditions}

Enterococcus mundtii CRL1656 was previously isolated from a healthy dairy cow and deposited in the CERELA Culture Collection (Espeche et al., 2009). Listeria innocua 7 (provided by the Unité de Recherches Laitiéres et Génetique Appliqueé, INRA, France) was used as an indicator strain and cultured in autolyzed yeast, peptone, tryptone, Tween 80 , and glucose (LAPTg; Raibaud et al., 1961) at $30^{\circ} \mathrm{C}$. Stock cultures were maintained in milk-yeast extract at $-70^{\circ} \mathrm{C}$. In- dividual components for LAPTg were obtained from Britania Laboratories (Buenos Aires, Argentina).

\section{Inoculum Preparation and Growth Experiments}

Enterococcus mundtii CRL1656 was subcultured 3 times in LAPTg broth at $37^{\circ} \mathrm{C}$. The active culture was centrifuged for $7 \mathrm{~min}$ at $10,000 \times g$ at room temperature. The supernatant was discarded and the bacterial pellet was washed twice with sterile saline solution $[0.85 \%$ (wt/vol) NaCl]. Optical density at $540 \mathrm{~nm}$ $\left(\mathbf{O D}_{540}\right)$ was adjusted in sterile saline solution to 0.7 (approximately $10^{9} \mathrm{cfu} / \mathrm{mL}$ ) and this suspension was used as the inoculum for different culture conditions.

The initial pH of LAPTg, de Man-Rogosa-Sharpe (MRS) broth (de Man et al., 1960; Merck, Darmstadt, Germany), or M17 (Terzaghi and Sandine, 1975) broth (Biokar Diagnostics, Beauvais, France) was adjusted to 5.0 or 6.5 with $2 M \mathrm{HCl}$ or $2 \mathrm{M} \mathrm{NaOH}$ before sterilization. Enterococcus mundtii CRL1656 was inoculated $[2.5(\mathrm{vol} / \mathrm{vol})$ or $5.0 \%(\mathrm{vol} / \mathrm{vol})]$ into tubes containing $4 \mathrm{~mL}$ of each culture medium. Then, aliquots for each of the conditions to be assayed were distributed into sterile tubes corresponding to each sampling time and incubated at a constant temperature of 30 or $37^{\circ} \mathrm{C}$, with (50 oscillations/min; incubator Dubnoff Model; Vicking S.R.L., Buenos Aires, Argentina) or without agitation (0 oscillations/min) as appropriate.

The responses evaluated were $\mathrm{OD}_{540}$ (as a measure of bacterial growth) and bacteriocin titer. Samples were taken after $0,3,6,9,12$, and $24 \mathrm{~h}$ from each culture condition and $\mathrm{OD}_{540}$ was recorded with a microplate reader (VersaMax, Molecular Devices LLC, Sunnyvale, $\mathrm{CA}$, ). Samples were centrifuged for $7 \mathrm{~min}$ at $10,000 \times g$ at room temperature and supernatants were neutralized with sterile $2 M \mathrm{NaOH}$. Bacteriocin titers were determined by the well diffusion assay with $L$. innocua 7 as indicator strain and expressed in arbitrary units (AU)/ $\mathrm{mL}$. The relative amount of bacteriocin produced per unit of biomass [calculated as $(\mathrm{AU} / \mathrm{mL}) / \mathrm{OD}_{540}$ ] was estimated for each culture condition for each time point.

\section{Experimental Design and Statistical Analysis}

A total of 48 different conditions were studied by applying a $3 \times 2^{4}$ full factorial design. The factors evaluated were culture medium (LAPTg, M17, and MRS), initial $\mathrm{pH}$ (5.0 and 6.5), inoculum size (2.5 and 5.0\%), incubation temperature $\left(30\right.$ and $\left.37^{\circ} \mathrm{C}\right)$, and agitation level ( 0 and 50 oscillations/min). The complete experimental design was repeated twice on different days. The randomization was performed for each experimental day. 
To estimate bacterial growth parameters, the modified Gompertz model with 4 parameters was applied (Zwietering et al., 1990) according to

$$
\mathrm{OD}_{t}=N_{0}+A \exp \{-\exp [(\mu e / A)(\lambda-t)+1]\}
$$

where $\mathrm{OD}_{t}=\mathrm{OD}$ at time $t ; N_{0}=$ initial value of $\mathrm{OD}$; $A=$ increase of OD between maximal OD and $N_{0} ; \mu$ $=$ growth rate expressed in $\mathrm{h}^{-1} ; \lambda=$ length of the lag phase in hours; $t=$ time expressed in hours; and $e=$ base of neperian logarithm (2.718281828).

Growth parameters were calculated using the constrained nonlinear regression with sequential quadratic programming method (Zwietering et al., 1990; Juarez Tomás et al., 2002). Standard errors were determined by the bootstrapping technique (SPSS Software 15.0, IBM, Armonk, NY). Estimations of the effects of culture medium, initial $\mathrm{pH}$, inoculum size, incubation temperature, and level of agitation on growth parameters were performed using a nonlinear mixed model (Lindstrom and Bates, 1990; S-Plus 7.2, TIBCO Software Inc., Palo Alto, CA).

To evaluate the effects of the different factors assayed on bacteriocin production, a linear mixed model was applied using the restricted maximum likelihood. The degrees of freedom were estimated using the Satterthwaite method (SAS Software 9.2, SAS Institute Inc., Cary, NC). A nonlinear model was used to study the effect of culture media, inoculum size, $\mathrm{pH}$, incubation temperature, and level of agitation on the $(\mathrm{AU} / \mathrm{mL}) /$ $\mathrm{OD}_{540}$ values.

\section{RESULTS}

\section{Effects of Physicochemical Factors on Lag Phase Length}

Culture medium, initial $\mathrm{pH}$, inoculum size, and incubation temperature exerted a significant effect on the duration of the lag phase (Tables 1 and 2). This phase was shorter in LAPTg than in $\operatorname{M17}(P=0.001)$ or MRS $(P=0.013)$. Initial $\mathrm{pH} 5.0$ produced lag phases longer than initial $\mathrm{pH} 6.5(P=0.0002)$. Incubation at $37^{\circ} \mathrm{C}$ and $5.0 \%$ inoculum originated lag phases shorter than at $30^{\circ} \mathrm{C}(P<0.0001)$ and $2.5 \%(P<0.0001)$, respectively. The shortest lag phase lengths were registered in LAPTg and M17, $\mathrm{pH} 6.5$, with $5 \%$ inoculum, at $37^{\circ} \mathrm{C}$, and with agitation (Table 2).

The longest lag phase (35.18 h,) was estimated using the Gompertz model in MRS, $\mathrm{pH} 5.0$, with $2.5 \%$ inoculum at $37^{\circ} \mathrm{C}$ under agitated conditions (assay 18,

Table 1. Estimation of the growth parameters of Enterococcus mundtii CRL1656 (at 2.5\% inoculum) using the modified Gompertz model

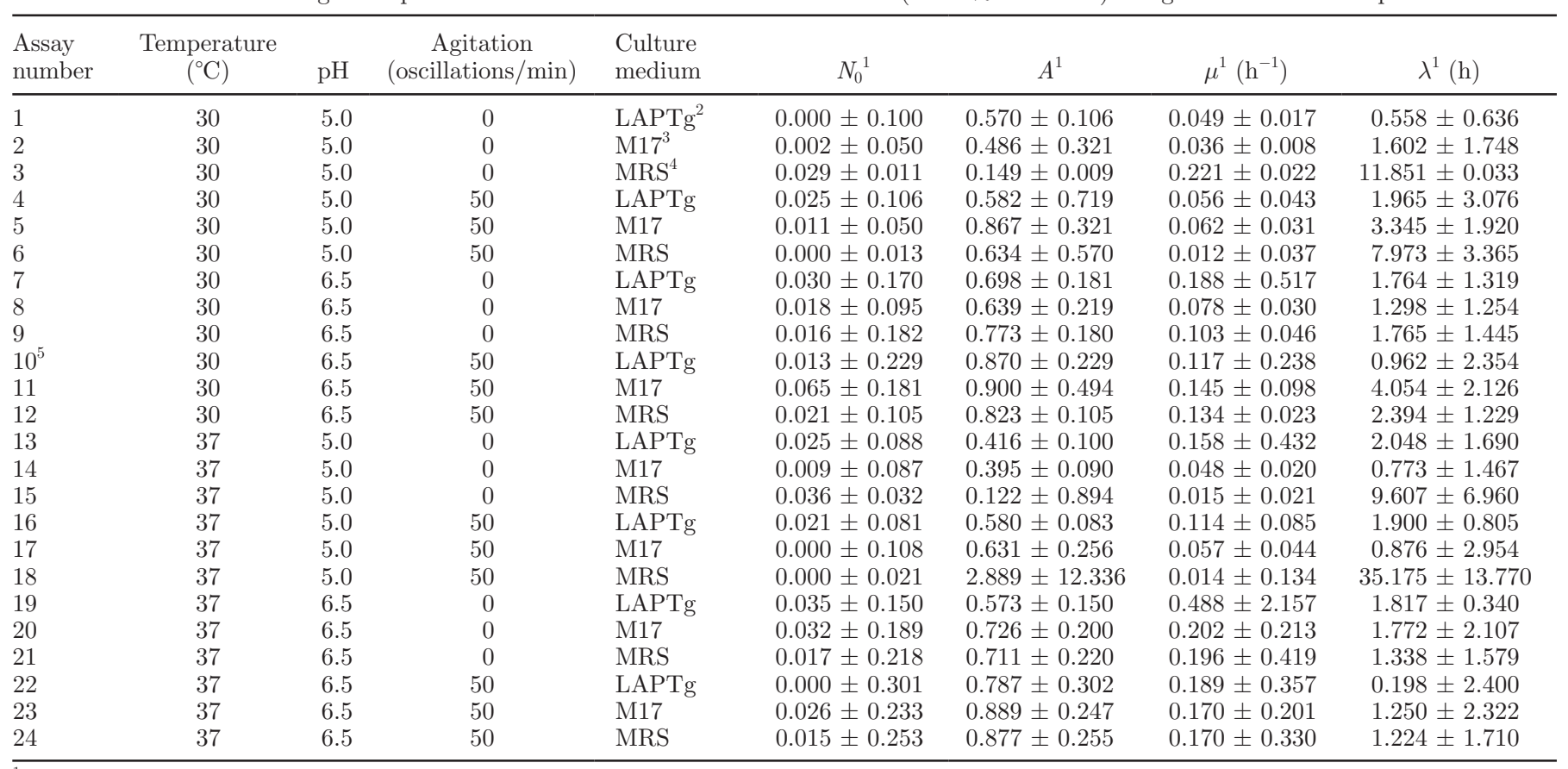

${ }^{1}$ Parameters of the Gompertz model: $N_{0}=$ initial optical density; $A=$ increase in biomass; $\mu=$ growth rate; $\lambda=$ lag phase. Each value represents the mean $\pm 95 \%$ CI.

${ }^{2}$ Autolyzed yeast, peptone, tryptone, Tween 80 (Merck, Darmstadt, Germany), and glucose (LAPTg) broth.

${ }^{3}$ M17 broth (Biokar Diagnostics, Beauvais, France).

${ }^{4}$ de Man-Rogosa-Sharpe (MRS) broth (Merck).

${ }^{5}$ Culture conditions in assay 10 enabled reaching both high biomass and bacteriocin levels. 
Table 2. Estimation of the growth parameters of Enterococus mundtii CRL1656 (at 5.0\% inoculum) using the modified Gompertz model

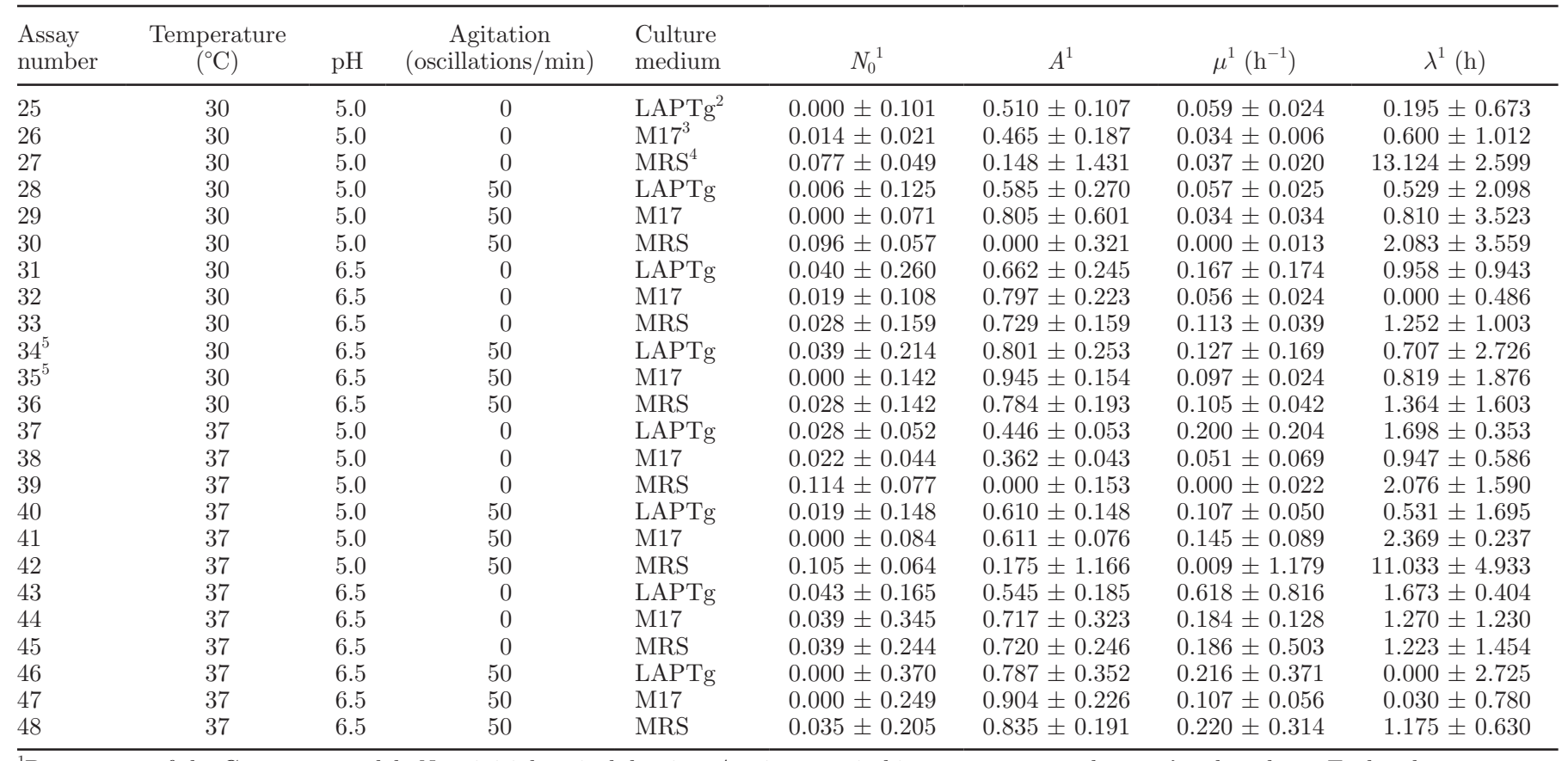

${ }^{1}$ Parameters of the Gompertz model: $N_{0}=$ initial optical density; $A=$ increase in biomass; $\mu=$ growth rate; $\lambda=$ lag phase. Each value represents the mean $\pm 95 \%$ CI.

${ }^{2}$ Autolyzed yeast, peptone, tryptone, Tween 80 (Merck, Darmstadt, Germany), and glucose (LAPTg) broth.

${ }^{3}$ M17 broth (Biokar Diagnostics, Beauvais, France).

${ }^{4}$ de Man-Rogosa-Sharpe (MRS) broth (Merck).

${ }^{5}$ Optimal growth conditions were observed in assays 34 and 35 .

Table 1). Also, a high biomass increase was mathematically estimated under these culture conditions. Only for assay 18 , however, was the calculated length of the lag phase higher than the duration of growth experiments $(24 \mathrm{~h})$, which indicated that the microorganism did not grow at all under these conditions (i.e., the increase of the estimated maximal biomass applying the Gompertz model was not observed experimentally during the sampling times assayed).

\section{Effects of Physicochemical Factors on Growth Rate}

Culture medium, $\mathrm{pH}$, temperature, and the interaction between medium and $\mathrm{pH}$ affected maximum growth rate values. The MRS $(P<0.0001)$ and M17 $(P<0.0001)$ broths produced a lower growth rate, whereas an initial $\mathrm{pH}$ of $6.5(P<0.0001)$ and an incubation temperature of $37^{\circ} \mathrm{C}(P<0.0001)$ generated the opposite effect. However, the effect of initial $\mathrm{pH}$ on growth rate depended on the culture medium used (i.e., the interaction between $\mathrm{pH}$ and culture medium was statistically significant). The highest growth rates were reached in LAPTg at $\mathrm{pH} 6.5$, at a temperature of $37^{\circ} \mathrm{C}$, under nonagitated conditions, and with the 2 inocula assayed (assays 19 and 43, Tables 1 and 2).

\section{Effects of Physicochemical Factors on the Increase in Biomass}

More factors had a significant effect on the increase in bacterial biomass than on lag phase or growth rate. The M17 medium caused an increase in final biomass $(P$ $<0.0001)$, whereas MRS produced the opposite effect $(P<0.0001)$. Initial pH $6.5(P<0.0001)$ and level of agitation $(P<0.0001)$ favored the increase in biomass, whereas a temperature of $37^{\circ} \mathrm{C}$ produced the opposite effect. The $\mathrm{pH}$-culture medium interaction was statistically significant $(P<0.0001)$, as seen in growth rate values. The increase in biomass was significantly higher in LAPTg $\mathrm{pH} 6.5$ than in LAPTg $\mathrm{pH}$ 5.5. The highest value of biomass was recorded with $5 \%$ inoculum in $\mathrm{M} 17 \mathrm{pH} 6.5$, at $30^{\circ} \mathrm{C}$, and agitation (assay 35, Table 2).

\section{Effects of Physicochemical Factors on Bacteriocin Production}

Culture medium $(P<0.0001)$, initial $\mathrm{pH}(P<$ $0.0001)$, and incubation temperature $(P=0.0002)$ affected the bacteriocin production (Figures 1 and 2). In general, higher bacteriocin levels (up to $76,800 \mathrm{AU} / \mathrm{mL}$ ) were obtained in MRS or LAPTg at an initial $\mathrm{pH}$ of 6.5 
and at $30^{\circ} \mathrm{C}$. Low levels of bacteriocin activity were detected in M17 broth. Bacteriocin production occurred during the exponential growth phase, continued during the early stationary phase, and reached a plateau, although in some cases activity decreased after $24 \mathrm{~h}$ incubation. Analysis of $(\mathrm{AU} / \mathrm{mL}) / \mathrm{OD}_{540}$ values for the different culture conditions showed that culture media $(P<0.0001)$, initial $\mathrm{pH}(P<0.001)$, and temperature $(P<0.001)$ had an influence on the bacteriocin levels per unit of biomass, as observed in bacteriocin production (data not shown).

\section{Optimal Conditions of Growth and Bacteriocin Production}

Better growth conditions were recorded in LAPTg and M17 broth at an initial $\mathrm{pH}$ of 6.5 with agitation (Tables 1 and 2 and Figure 3). The optimal conditions to produce higher biomass (shorter lag phase, greater biomass increase, and maximum growth rate) were obtained with $5.0 \%$ inoculum in M17 or LAPTg medium at $\mathrm{pH} 6.5$, incubated at $30^{\circ} \mathrm{C}$ with agitation (assays 34 and 35 , Table 2).
The optimal mundticin CRL1656 production was obtained in LAPTg at an initial $\mathrm{pH} 6.5$ with $2.5 \%$ inoculum, at $30^{\circ} \mathrm{C}$, with or without agitation (Figure 1). Under these conditions, the maximum bacteriocin levels reached were 76,800 (after $9 \mathrm{~h}$ of incubation with agitation) and $64,000 \mathrm{AU} / \mathrm{mL}$ (after $12 \mathrm{~h}$ of incubation without agitation). Optimal bacteriocin or biomass ratios were obtained in (a) LAPTg, $\mathrm{pH} 6.5,2.5 \%$ inoculum, at $30^{\circ} \mathrm{C}$ with agitation, (b) LAPTg, $\mathrm{pH} 6.5,2.5 \%$ inoculum, at $37^{\circ} \mathrm{C}$ without agitation, and (c) MRS or LAPTg, $5.0 \%$ inoculum, $\mathrm{pH} 6.5$, at $30^{\circ} \mathrm{C}$ without agitation (Figure 3). The culture conditions that promoted the highest production of biomass and bacteriocin were LAPTg medium, $\mathrm{pH} 6.5,2.5 \%$ inoculum, incubated at $30^{\circ} \mathrm{C}$ with agitation (assay 10 , Table 1 ).

\section{DISCUSSION}

Over the last few years, scientific evidence has shown the effectiveness of beneficial microorganisms (Klostermann et al., 2008; Beecher et al., 2009; Frola et al., 2012) or bacteriocins from LAB (Crispie et al., 2004; Cao et al., 2007; Pieterse et al., 2010) in the pre-

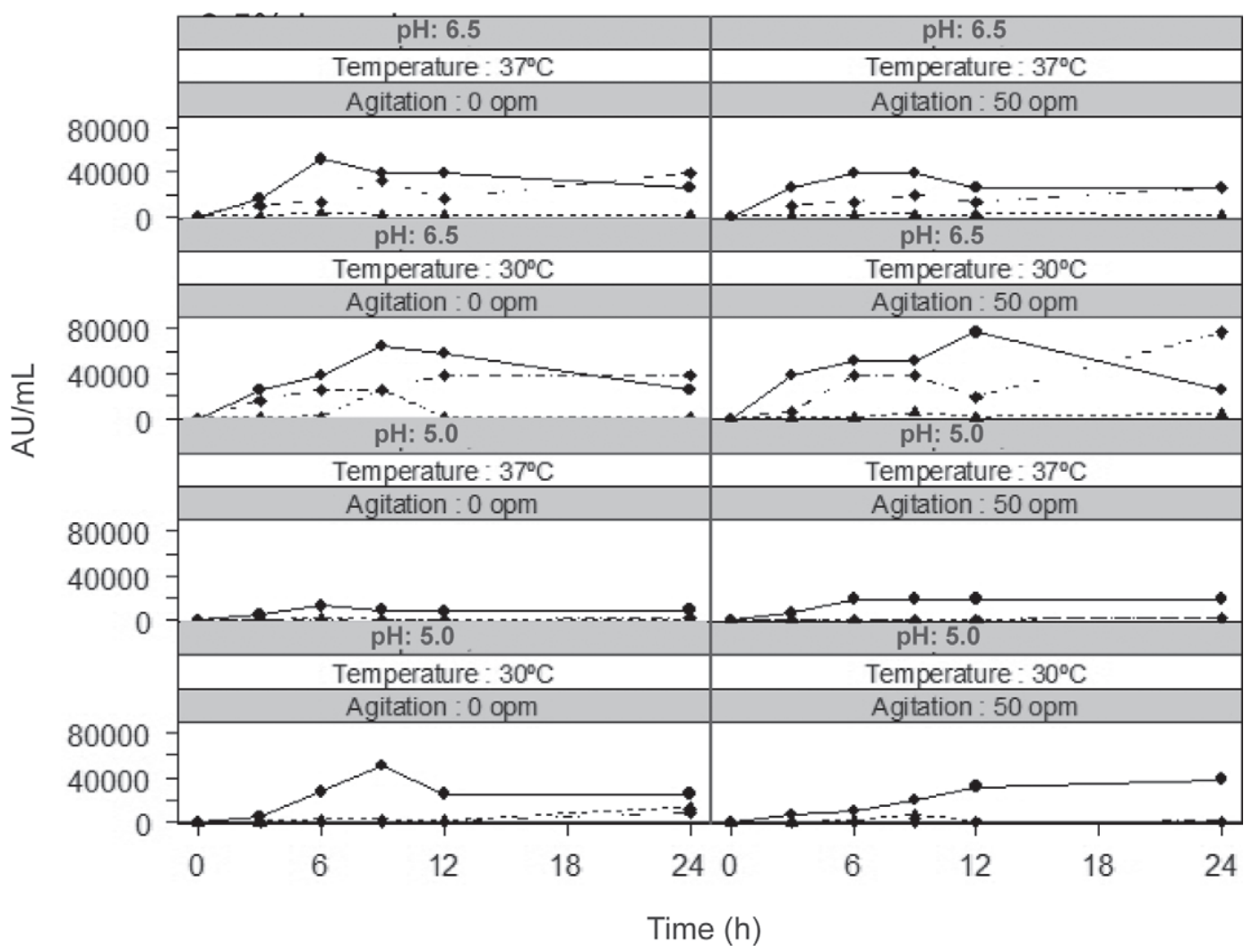

Figure 1. Kinetics of bacteriocin production [as arbitrary units $(\mathrm{AU}) / \mathrm{mL}$ ] by Enterococcus mundtii CRL1656 at $2.5 \%$ inoculum, in autolyzed yeast, peptone, tryptone, Tween 80, and glucose broth $(\bullet)$; de Man-Rogosa-Sharpe broth $(\bullet)$; and M17 broth $(\mathbf{\Delta})$ under different initial pH and agitation conditions. opm $=$ oscillations per minute. 


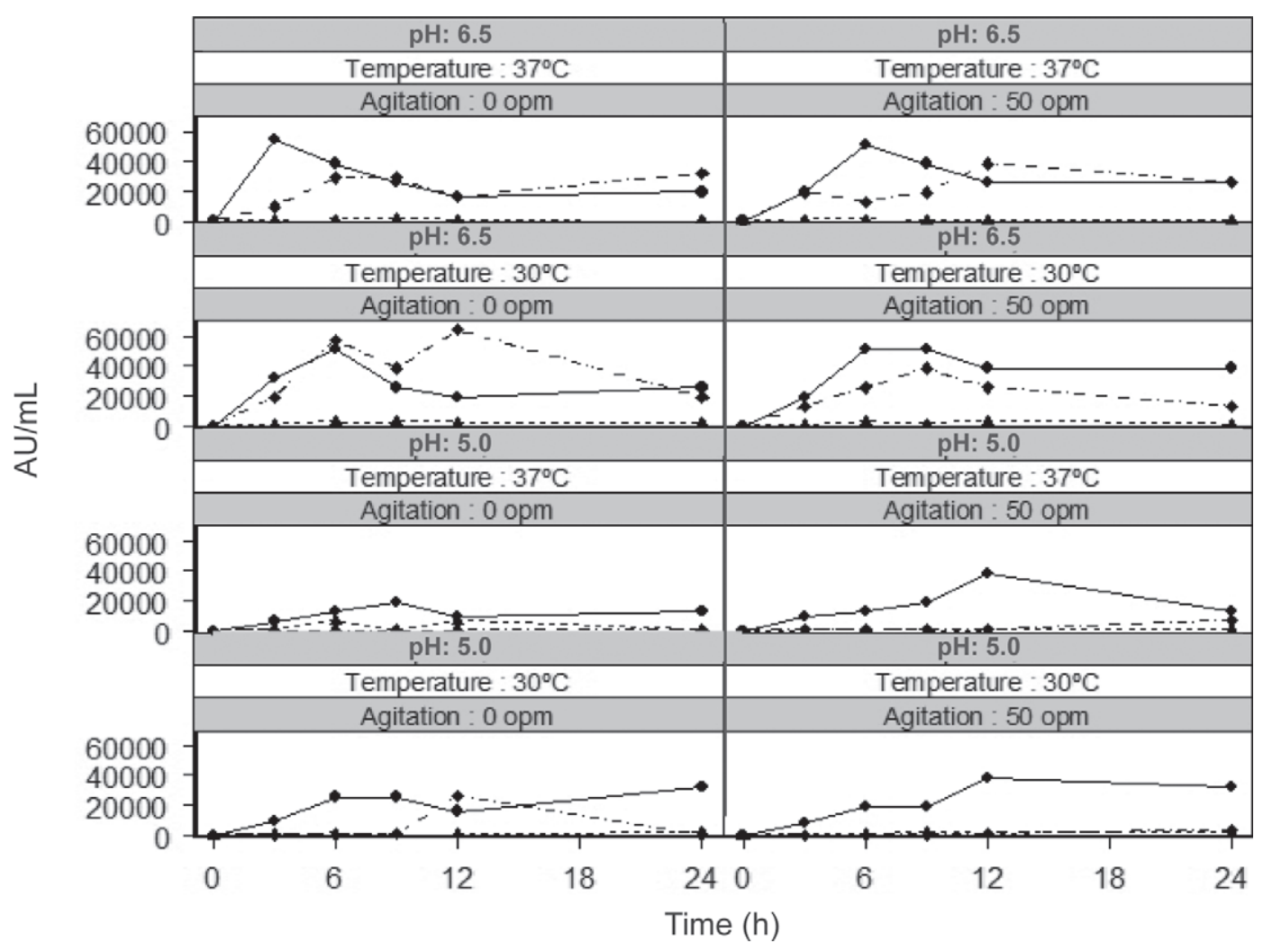

Figure 2. Kinetics of bacteriocin production [as arbitrary units (AU)/mL] by Enterococcus mundtii CRL1656 at $5.0 \%$ inoculum, in autolyzed yeast, peptone, tryptone, Tween 80, and glucose broth $(\bullet)$; de Man-Rogosa-Sharpe broth $(\diamond)$; and M17 broth $(\boldsymbol{\Delta})$ under different initial pH and agitation conditions. opm $=$ oscillations per minute.

vention or treatment of bovine mastitis. In this study, the simultaneous evaluation of the effect of different factors on the growth and bacteriocin production of a bovine E. mundtii strain was performed using a full factorial design. Biomass and bacteriocin production by E. mundtii CRL1656 was found to depend mainly on culture medium, initial $\mathrm{pH}$, and temperature, as evidenced in other bacteriocinogenic LAB, such as $E$. mundtii ST15, ST4SA, and QU 2 (De Kwaadsteniet et al., 2005; Zendo et al., 2005; Todorov and Dicks, 2009), Streptococcus macedonicus ACA-DC 198 (Van den Berghe et al., 2006), and Pediococcus damnosus NCFB 1832 (Nel et al., 2001). Previously, culture medium components and $\mathrm{pH}$ have been shown to strongly influence bacteriocin production of E. mundtii ST4SA (Coetzee et al., 2007). Optimal levels were obtained in corn stern liquor supplemented with yeast extract and glucose, and the level of production was maintained by adjusting the $\mathrm{pH}$ culture during the fermentation. Others have found that culture medium and initial $\mathrm{pH}$, but not temperature, significantly affected the activity of bacteriocins produced by various E. mundtii strains of raw material of vegetable origin (Settanni et al., 2008).
In the case of E. mundtii CRL1656, the effect of $\mathrm{pH}$ on several growth parameters was dependent on the culture medium assayed. This interaction between factors would not be observed using a single factor approach. In general, inoculum size and level of agitation did not produce a significant effect on biomass and bacteriocin production, although $5.0 \%$ inoculum significantly reduced the length of the lag phase. The increase in biomass and mundticin CRL1656 production was inversely related to the incubation temperature, reaching higher levels at 30 than $37^{\circ} \mathrm{C}$. In a similar way, higher bacteriocin production at lower temperatures $(25$ or $30^{\circ} \mathrm{C}$ ) was reported for E. mundtii ST15, ST4SA, and QU 2 (De Kwaadsteniet et al., 2005; Zendo et al., 2005; Todorov and Dicks, 2009).

It is well known that bacteriocin production is sometimes higher at suboptimal growth conditions, such as low pH (De Vuyst et al., 1996; Juarez Tomás et al., 2002; Todorov and Dicks, 2009). For example, the highest bacteriocin production of E. mundtii QU 2 was achieved at $\mathrm{pH}$ 6.0, whereas the highest cell growth was obtained at pH 7.0 (Zendo et al., 2005). In contrast, in the case of E. mundtii CRL1656, optimal pH for biomass and bacteriocin production was the same. A lower 

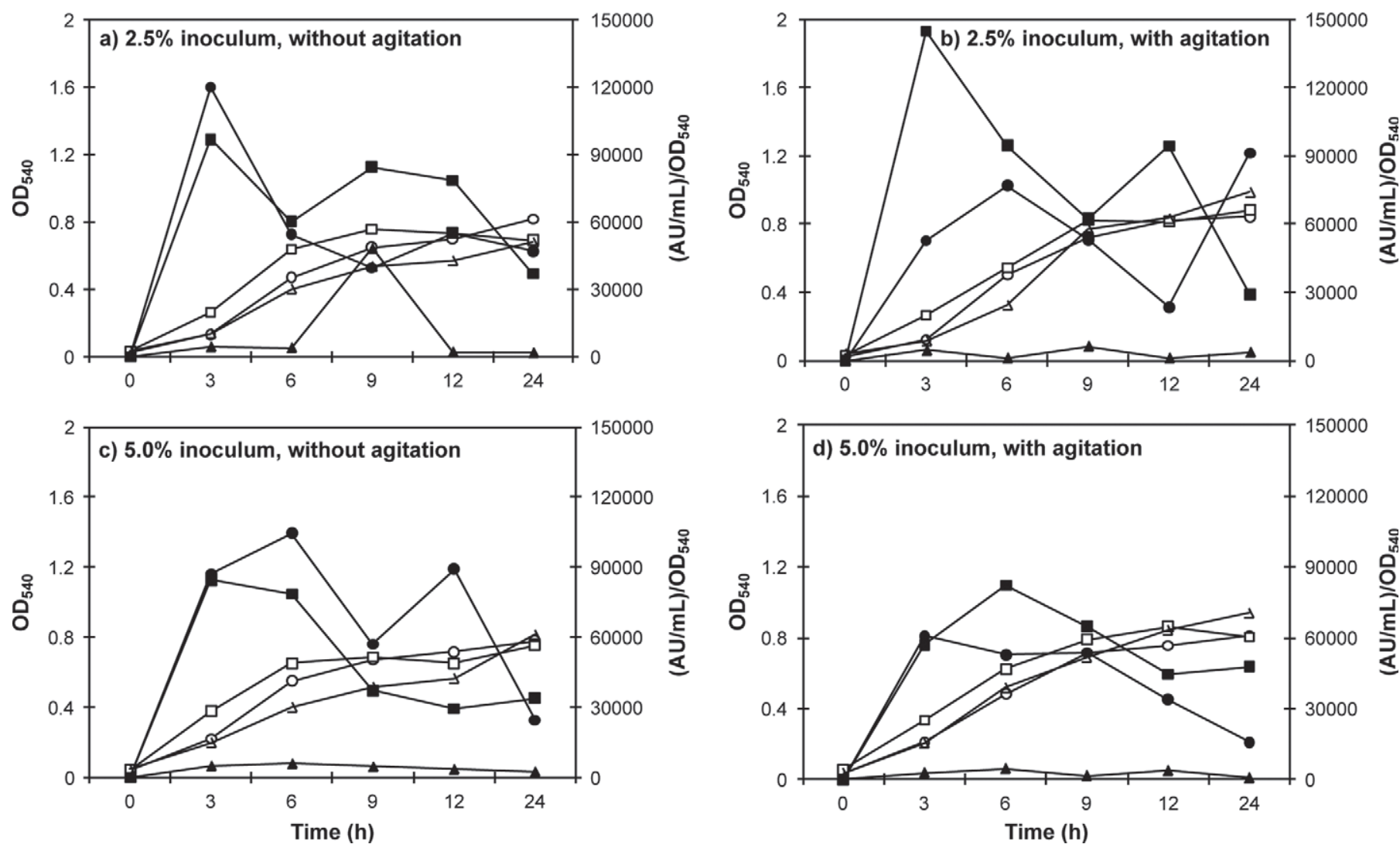

Figure 3. Kinetics of growth [as optical density at $\left.540 \mathrm{~nm}\left(\mathrm{OD}_{540}\right)\right]$ and bacteriocin production [as arbitrary units $\left.(\mathrm{AU}) / \mathrm{mL}\right] \mathrm{per}$ unit of biomass [i.e., $(\mathrm{AU} / \mathrm{mL}) / \mathrm{OD}_{540}$ ] of Enterococcus mundtii $\mathrm{CRL} 1656$ under optimal $\mathrm{pH}$ and temperature conditions $\left(6.5\right.$ and $30^{\circ} \mathrm{C}$, respectively) at different inoculum levels, culture media, and agitation conditions. The $\mathrm{OD}_{540}$ in autolyzed yeast, peptone, tryptone, Tween 80 , and glucose broth $=\mathrm{O}$, de Man-Rogosa-Sharpe broth $=\square$, and M17 broth $=\Delta ;(\mathrm{AU} / \mathrm{mL}) / \mathrm{OD}_{540}$ in autolyzed yeast, peptone, tryptone, Tween 80 , and glucose broth $=\boldsymbol{\bullet}$, de Man-Rogosa-Sharpe broth $=\mathbf{\square}$, and M17 broth $=\boldsymbol{\Lambda}$.

production of biomass and bacteriocins by E. mundtii CRL1656 was recorded at an initial $\mathrm{pH}$ of 5.0 than at $\mathrm{pH}$ 6.5. In a similar way, low $\mathrm{pH}$ values (from 4.0 to 5.5) did not favor the bacteriocin production of several E. mundtii strains isolated from vegetables (De Kwaadsteniet et al., 2005; Zendo et al., 2005; Settanni et al., 2008; Todorov and Dicks, 2009). The optimal pH value (6.5) for the growth and bacteriocin production of $E$. mundtii CRL1656 is udder skin compatible (Hemling, 2002); therefore, the results obtained allow a prediction of the behavior of the strain once administered to the host.

Maximal levels of biomass and bacteriocins and of bacteriocin produced per unit of biomass were obtained in different culture media for $E$. mundtii CRL1656. The highest amount of biomass was obtained in LAPTg and M17 broth for this strain, whereas bacteriocin activity was maximal in LAPTg and MRS but minimal in M17. Similar results were observed in different bacteriocinproducing E. mundtii strains that showed the lowest bacteriocin activity in M17 medium (De Kwaadsteniet et al., 2005; Settanni et al., 2008; Todorov and Dicks, 2009).
Several differences in culture medium components between M17 (a culture medium used for the growth of lactococci and streptococci; Terzaghi and Sandine, 1975) and LAPTg and MRS (media frequently used for LAB; De Man et al., 1960; Raibaud et al., 1961) would account for the low bacteriocin production recorded for E. mundtii CRL1656 grown in M17. For example, M17 contains lactose as a carbon source instead of glucose, which is included in LAPTg and MRS. Conversely, total concentration of nitrogen sources in M17 (17.5 $\mathrm{g} / \mathrm{L}$ ) is lower than in LAPTg and MRS (35 and $25 \mathrm{~g} / \mathrm{L}$, respectively). Besides, unlike LAPTg and MRS, M17 does not contain Tween 80, a source of FA considered a growth stimulant of several LAB. Zendo et al. (2005) reported that bacteriocin production by E. mundtii QU 2 decreased in MRS broth depleted of glucose, nitrogen sources, or Tween 80. In a similar way, the inclusion of Tween 80 in the growth medium of E. mundtii ST4SA increased bacteriocin production by more than $50 \%$ (Todorov and Dicks, 2009).

Mundticin CRL1656 was produced during the exponential phase and at the beginning of the stationary 
growth phase. This means that bacteriocin production is associated with the growth of E. mundtii CRL1656 as a primary metabolite. Other researchers also reported bacteriocin production during the log phase (e.g., E. mundtii ST4SA, Lactococcus lactis A164, and Lactobacillus amylovorus DCE 471; De Vuyst et al., 1996; Cheigh et al., 2002; Todorov and Dicks, 2009). The decrease in mundticin CRL1656 activity observed during the stationary phase could be caused by the adsorption of the bacteriocin onto the bacterial surface, or by protein aggregation or proteolytic degradation (De Vuyst et al., 1996; De Vuyst and Leroy, 2007).

In conclusion, several physicochemical factors affected the growth and mundticin CRL1656 production by an autochthonous beneficial E. mundtii CRL1656 from the bovine udder, depending on the response evaluated. The most favorable culture conditions for biomass and bacteriocin production were reached in LAPTg medium, at an initial $\mathrm{pH}$ of 6.5 , with $2.5 \%$ inoculum, incubated at $30^{\circ} \mathrm{C}$ under agitation. These results represent an advance in the optimization of the culture conditions to obtain high levels of raw material (biomass and antimicrobial metabolite) that can be included in a probiotic product for bovine mastitis prevention. Further studies are needed for the design of different low cost alternative media to achieve simultaneous optimal biomass and bacteriocin production.

\section{ACKNOWLEDGMENTS}

This work was financially supported by the Consejo Nacional de Investigaciones Científicas y Técnicas de Argentina (Buenos Aires, Argentina; PIP 632 and PIP 744), Agencia Nacional de Promoción Científica y Tecnológica (Buenos Aires, Argentina; PICT 2007-543 and PICT 2012-1187), and was performed within the framework of a Bilateral Cooperation Project (ARG 07/006) between the Ministerio de Ciencia, Tecnología e Innovación Productiva (Buenos Aires, Argentina) and Bundesministerium für Bildung und Forschung (Bonn, Germany).

\section{REFERENCES}

Barkema, H. W., M. J. Green, A. J. Bradley, and R. N. Zadoks. 2009. Invited review: The role of contagious disease in udder health. J. Dairy Sci. 92:4717-4729.

Beecher, C., M. Daly, D. P. Berry, K. Klostermann, J. Flynn, W. Meaney, C. Hill, T. V. McCarthy, R. P. Ross, and L. Giblin. 2009. Administration of a live culture of Lactococcus lactis DPC 3147 into the bovine mammary gland stimulates the local host immune response, particularly IL-1 and IL-8 gene expression. J. Dairy Res. 76:340-348.

Boddie, R. L., and S. C. Nickerson. 1992. Evaluation of postmilking teat germicides containing Lauricidin, saturated fatty acids, and lactic acid. J. Dairy Sci. 75:1725-1730.
Boddie, R. L., W. E. Owens, C. J. Foret, and P. Janowicz. 2004. Efficacy of a $0.1 \%$ iodine teat dip against Staphylococcus aureus and Streptococcus agalactiae during experimental challenge. J. Dairy Sci. 87:3089-3091.

Cao, L. T., J. Q. Wu, F. Xie, S. H. Hu, and Y. Mo. 2007. Efficacy of nisin in treatment of clinical mastitis in lactating dairy cows. J. Dairy Sci. 90:3980-3985.

Cheigh, C. I., H. J. Choi, H. Park, S. B. Kim, M. C. Kook, T. S. Kim, J. K. Hwang, and Y. R. Pyun. 2002. Influence of growth conditions on the production of a nisin-like bacteriocin by Lactococcus lactis ssp. lactis A164 isolated from kimchi. J. Biotechnol. 95:225-235.

Coetzee, J., S. Todorov, J. Görgens, and L. Dicks. 2007. Increased production of bacteriocin ST4SA by Enterococcus mundtii ST4SA in modified corn steep liquor. Ann. Microbiol. 57:617-622.

Crispie, F., J. Flynn, R. P. Ross, C. Hill, and W. J. Meaney. 2004. Update on the development of a novel dry cow therapy using a bismuth-based intramammary teat seal in combination with the bacteriocin lacticin 3147. Ir. Vet. J. 57:652-656.

De Kwaadsteniet, M., S. D. Todorov, H. Knoetze, and L. M. Dicks. 2005. Characterization of a 3944 Da bacteriocin, produced by Enterococcus mundtii ST15, with activity against Gram-positive and Gram-negative bacteria. Int. J. Food Microbiol. 105:433-444.

de Man, J. C., M. Rogosa, and M. E. Sharpe. 1960. A medium for the cultivation of lactobacilli. J. Appl. Bacteriol. 23:130-135.

De Vuyst, L., R. Callewaert, and K. Crabbé. 1996. Primary metabolite kinetics of bacteriocin biosynthesis by Lactobacillus amylovorus and evidence for stimulation of bacteriocin production under unfavourable growth conditions. Microbiology 142:817-827.

De Vuyst, L., and F. Leroy. 2007. Bacteriocins from lactic acid bacteria: Production, purification, and food applications. J. Mol. Microbiol. Biotechnol. 13:194-199.

Espeche, M. C., M. C. Otero, F. Sesma, and M. E. F. Nader-Macías. 2009. Screening of surface properties and antagonistic substances production by lactic acid bacteria isolated from the mammary gland of healthy and mastitic cows. Vet. Microbiol. 135:346-357.

Frola, I. D., M. S. Pellegrino, M. C. Espeche, J. A. Giraudo, M. E. Nader-Macías, and C. I. Bogni. 2012. Effects of intramammary inoculation of Lactobacillus perolens CRL1724 in lactating cows' udders. J. Dairy Res. 79:84-92.

Granger, M., S. D. Todorov, M. K. Matthew, and L. M. Dicks. 2005. Growth of Enterococcus mundtii ST15 in medium filtrate and purification of bacteriocin ST15 by cation-exchange chromatography. J. Basic Microbiol. 45:419-425.

Hemling, T. C. 2002. Teat condition-Prevention and cure through teat dips. Pages 1-14 in Proc. British Mastitis Conf. Inst. Animal Health/Milk Develop. Counc., The Dairy Group, Taunton, UK.

Huijps, K., T. J. Lam, and H. Hogeveen. 2008. Costs of mastitis: Facts and perception. J. Dairy Res. 75:113-120.

Juarez Tomás, M. S., E. Bru, B. Wiese, A. A. P. De Ruiz Holgado, and M. E. Nader-Macías. 2002. Influence of $\mathrm{pH}$, temperature and culture media on the growth and bacteriocin production by vaginal Lactobacillus salivarius CRL 1328. J. Appl. Microbiol. 93:714724 .

Klostermann, K., F. Crispie, J. Flynn, W. J. Meaney, R. Paul Ross, and C. Hill. 2010. Efficacy of a teat dip containing the bacteriocin lacticin 3147 to eliminate Gram-positive pathogens associated with bovine mastitis. J. Dairy Res. 77:231-238.

Klostermann, K., F. Crispie, J. Flynn, R. P. Ross, C. Hill, and W. Meaney. 2008. Intramammary infusion of a live culture of Lactococcus lactis for treatment of bovine mastitis: Comparison with antibiotic treatment in field trials. J. Dairy Res. 75:365-373.

Lindstrom, M. L., and D. M. Bates. 1990. Nonlinear mixed effects models for repeated measures data. Biometrics 46:673-687.

Mataragas, M., J. Metaxopoulos, M. Galiotou, and E. H. Drosinos. 2003. Influence of $\mathrm{pH}$ and temperature on growth and bacteriocin production by Leuconostoc mesenteroides L124 and Lactobacillus curvatus L442. Meat Sci. 64:265-271.

Nel, H. A., R. Bauer, E. J. Vandamme, and L. M. T. Dicks. 2001. Growth optimization of Pediococcus damnosus NCFB 1832 and the influence of $\mathrm{pH}$ and nutrients on the production of pediocin PD-1. J. Appl. Microbiol. 91:1131-1138. 
Pieterse, R., and S. D. Todorov. 2010. Bacteriocins-Exploring alternatives to antibiotics in mastitis treatment. Braz. J. Microbiol. 41:542-562.

Pieterse, R., S. D. Todorov, and L. M. Dicks. 2008. Bacteriocin ST91KM, produced by Streptococcus gallolyticus ssp. macedonicus ST91KM, is a narrow-spectrum peptide active against bacteria associated with mastitis in dairy cattle. Can. J. Microbiol. 54:525-531.

Pieterse, R., S. D. Todorov, and M. T. D. Leon. 2010. Mode of action and in vitro susceptibility of mastitis pathogens to macedocin ST91KM and preparation of a teat seal containing the bacteriocin. Braz. J. Microbiol. 41:133-145.

Raibaud, P., M. Caulet, J. V. Galpín, and G. Mocquot. 1961. Studies on the bacterial flora of the alimentary tract of pigs. II. Streptococci: Selective enumeration of the dominant groups. J. Appl. Bacteriol. 24:285-306.

Salvucci, E., L. Saavedra, E. M. Hebert, C. Haro, and F. Sesma. 2012. Enterocin CRL35 inhibits Listeria monocytogenes in a murine model. Foodborne Pathog. Dis. 9:68-74.

Sears, P. M., and K. K. McCarthy. 2003. Management and treatment of staphylococcal mastitis. Vet. Clin. North Am. Food Anim. Pract. 19:171-185.

Sears, P. M., B. S. Smith, W. K. Stewart, R. N. Gonzalez, S. D. Rubino, S. A. Gusik, E. S. Kulisek, S. J. Projan, and P. Blackburn. 1992. Evaluation of a nisin-based germicidal formulation on teat skin of live cows. J. Dairy Sci. 75:3185-3190.

Settanni, L., S. Valmorri, G. Suzzi, and A. Corsetti. 2008. The role of environmental factors and medium composition on bacteriocin-like inhibitory substances (BLIS) production by Enterococcus mundtii strains. Food Microbiol. 25:722-728.

Taponen, S., and S. Pyörälä. 2009. Coagulase-negative staphylococci as cause of bovine mastitis - Not so different from Staphylococcus aureus? Vet. Microbiol. 134:29-36.

Terzaghi, B. E., and W. E. Sandine. 1975. Improved medium for lactic streptococci and their bacteriophages. Appl. Microbiol. 29:807813.

Todorov, S. D., and L. M. T. Dicks. 2009. Effect of modified MRS medium on production and purification of antimicrobial peptide ST4SA produced by Enterococcus mundtii. Anaerobe 15:65-73.

Van den Berghe, E., G. Skourtas, E. Tsakalidou, and L. De Vuyst. 2006. Streptococcus macedonicus ACA-DC 198 produces the lantibiotic, macedocin, at temperature and $\mathrm{pH}$ conditions that prevail during cheese manufacture. Int. J. Food Microbiol. 107:138-147.

Vera Pingitore, E., S. D. Todorov, F. Sesma, and B. D. Franco. 2012 Application of bacteriocinogenic Enterococcus mundtï CRL35 and Enterococcus faecium ST88Ch in the control of Listeria monocytogenes in fresh Minas cheese. Food Microbiol. 32:38-47.

Zendo, T., N. Eungruttanagorn, S. Fujioka, Y. Tashiro, K. Nomura, Y. Sera, G. Kobayashi, J. Nakayama, A. Ishizaki, and K. Sonomoto. 2005. Identification and production of a bacteriocin from Enterococcus mundtii QU 2 isolated from soybean. J. Appl. Microbiol. 99:1181-1190.

Zwietering, M. H., I. Jongenburger, F. M. Rombouts, and K. Van't Riet. 1990. Modeling of the bacterial growth curve. Appl. Environ. Microbiol. 56:1875-1881. 